The Version of Record of this manuscript has been published and is available in:

Performance Research Vol. 23 No. 7, 31 January 2019,

https://www.tandfonline.com/doi/abs/10.1080/13528165.2018.1557009

Page layout and design: Stephen Hodge

\begin{abstract}
Where to build the walls that protect us

Stephen Hodge
\end{abstract}

Working at a tangent to Wrights \& Sites' disrupted walking practices and the notion of the architect-walker, commissioned by Kaleider and funded by Arts Council England, Where to build the walls that protect us was an opportunity to imagine a future city. Originally focused on Exeter in 2013-14, the work was later reiterated for Leeds as part of Compass Festival 2016. Framed as an architectural charrette, participants experienced two distinct phases of activity: initially framed by a series of themed reconnaissance excursions; later followed by an iterative period of generating future-facing models of the city.

Literal and poetic drift underpinned the work, for example, through the use of:

- post-Situationist walking-art practices drawn from Wrights \& Sites and others, e.g. Simon Pope's 'constrained drift', where geographical (or temporal) limits bound the scope of the journey;

- strategic, location-specific encounters with 'experts' (whether professional, municipal or resident), as spurs to the imagination;

- creative intervention into the process of city planning (Exeter was undertaking a consultation process about its new flood defence scheme at the time);

- physical interruption of everyday city life, as unsuspecting members of the public suspended their A to $B$ journeys and join in the reimagining of their city. 
Where to build the walls that protect us. The flood defences? Your home? The bounds of the city?

We walked these streets. Remember? Over and over. Walking and talking together. About the things we'd need to consider if starting again from scratch. About the land and the weather. About the buildings and the life between them. About money. How we earn it and spend it. About how things join up. How we get around and communicate. And, along the way, we met other people. Climate scientists. City planners. Community leaders. Long-term residents.

'What are our upstream and downstream connectivities and responsibilities?' we asked. 'Should we govern by watersheds, by fluid systems, by the network of flows?' Green spaces. Blue spaces. Brown spaces. Tipping points. The city a volcano. The city a shallow sea. The city a desert. A forageable city. A 1 in 100 chance in any one year. 'How will it age?' we asked. 'What will it look like in twenty years?' 'These rocks on the grass verge bordered by a railing - a lamppost, two lampposts, crooked sign, triage sign and beautiful curved curb,' we said. 'It's not harmonic - it could so easily be - the tree - the bin. We want to reposition ever so slightly and make this beautiful.' 'The only way to completely model the city is the city,' we said. 'Why do people pause?' we asked. THIS IS NOT A PLAY AREA. Where is the mystery and melancholy of a street? Superfluous sites. Temporary and portable structures. Animals. Places of memory. What is public space anyway? Little boxes all the same. Necessary activities. Optional activities. Social activities. Minimize. Maximize. The future of street furniture. 'Tweaks or Masterplans?' we asked. 'Animate the rooftops,' we said. 'Let's hang our washing out over the streets.' What will drive our city economically? Forget Utopian visions. Don't worry about logistics. Scan the horizon. Recycle. Reconfigure. Detourn. 'Two days ago we drove to the dentist and it took us longer than to walk,' we said. 'We felt a bit sick.' 'Three sheep could fit on an airport bus,' we said. 'We like to see escape routes,' we said. 'Views, glimpses of other routes, choices and gaps.' What's the best way to get ourselves from $A$ to $B$ ? How can we hardwire our desire paths into the fabric of the city? Think like a freerunner. A skateboarder. A visitor. Green. Amber. Red.

What are we going to do about these rising water levels? Should we build more walls? Retreat to the hills? Conceive new liquid architectures? Can we each contribute to turning off the tap? Is there even a tap? Are there solutions? Or just a tsunami of questions? It's not too late to feel hopeful, surely? 'Leaking,' the architect Cedric Price said, 'is best observed in a floating boat.'

\section{Where to build the walls that protect us.}

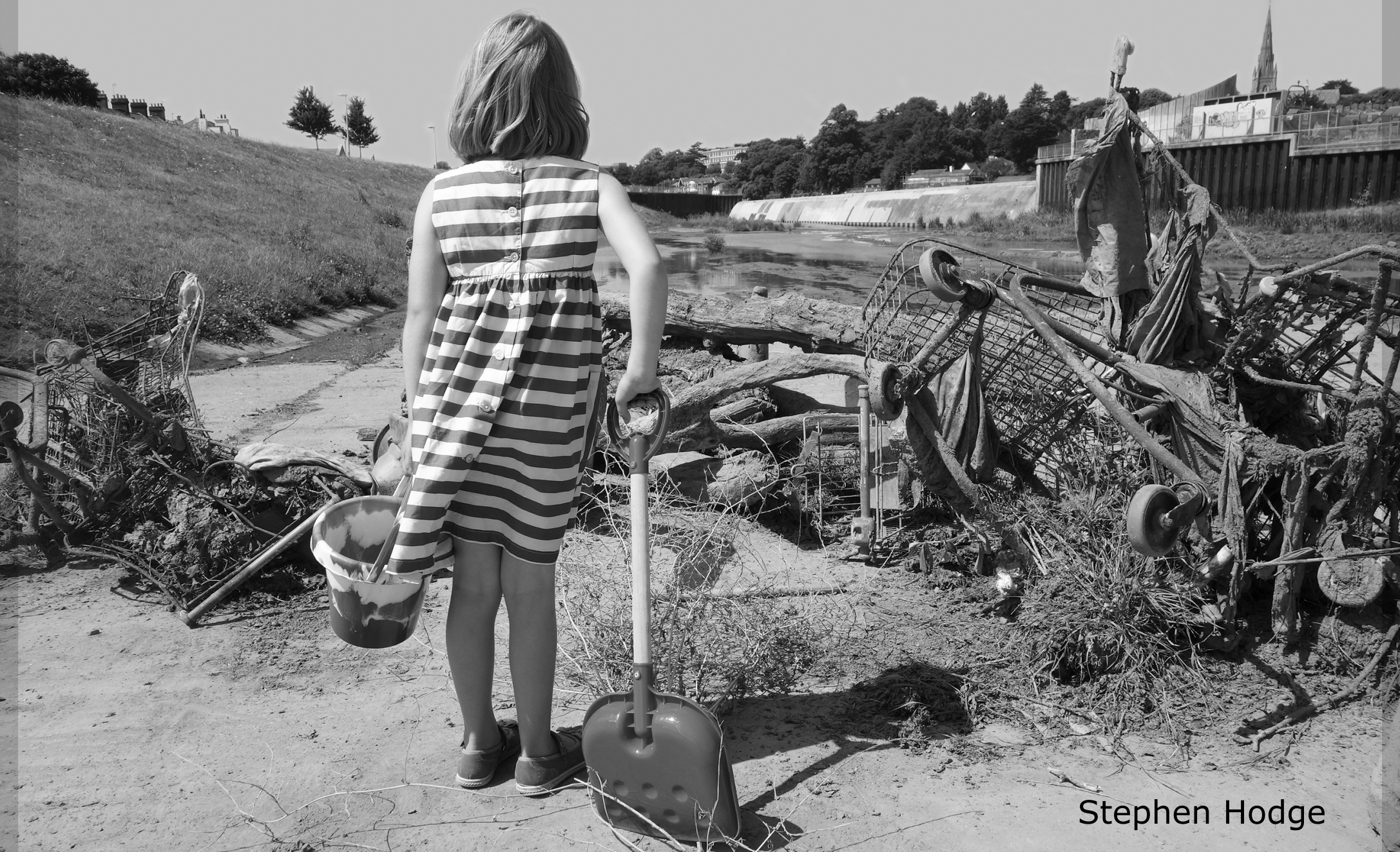




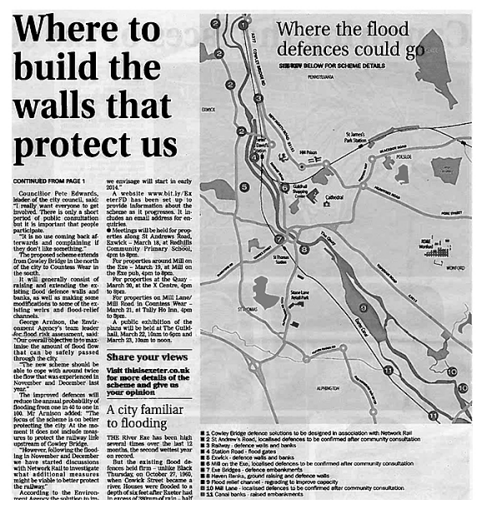

An architect or planner might call this sort of process a 'charrette' - an intensive, collaborative enquiry that seeks to solve a complex design issue. Perhaps that sounds rather dry and dusty, but you should be assured that this was an exercise in serious play - an exercise that sought to mine the ground between the Possible and the Imaginable.

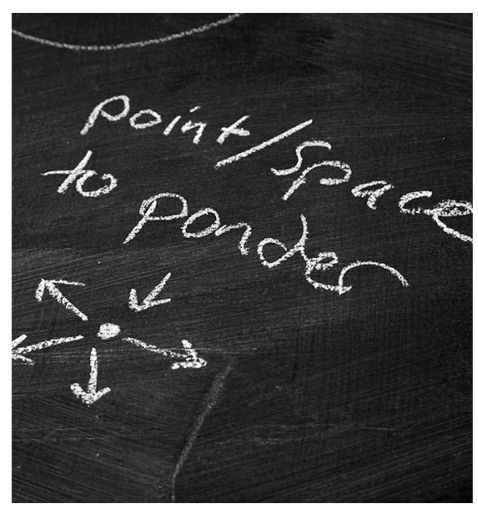

Mark McCarthy, from the UK's Meteorological Office employed bubbles, jars of rainwater and Lego to illustrate urban airflow, heat islands and the importance green, brown and blue spaces in the city. He initiated collective mental drifts that provoked thoughts of roof sponges and high-rise meadows, of edible urban oases and fruit routes.

In the redeveloped grounds of the former Exeter Borough Asylum, we paused to look at and discuss our individual desire paths. In a nod to Dan Belasco-Rogers, we made maps of our habitual movements through the city. We shared our autotopological knowledge and blind spots, our cravings and our aptitude as cartographers.
Originally commissioned by Kaleider, Exeter, and later reiterated for Compass Festival, Leeds, 'Where to build the walls that protect us' borrowed its title from an Exeter Express \& Echo newspaper headline relating to the city's future flood defences. Dislocated from its initial context, though, perhaps it feels more potent, more hopeful a provocation.

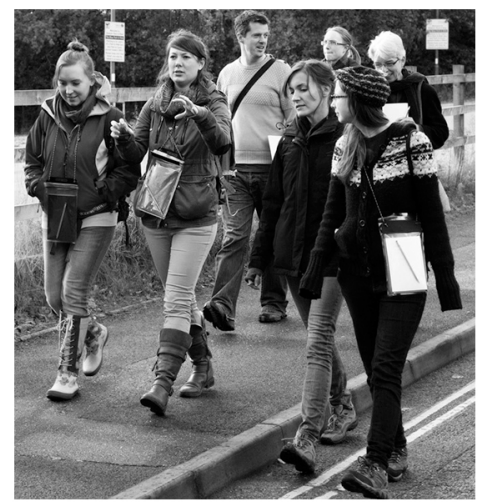

Walking and talking, or 'twalking', or 'walkshops' as method. It drew on the post-Situationist walking-art practices of Wrights \& Sites and others, e.g. Simon Pope's 'constrained drift', in which the overall trajectory and key landmarks may be known, but where there is a degree of geographical (or temporal) latitude for the participants to explore.

In nearby Cranbrook, Devon's first new town for 600 years, we met the Reverend Mark Gilborson. A building site with no shops yet, only one communal building (the school), four sets of show homes and a growing number of residents, who Mark personally greets and connects up via social media. He's building a community from scratch.

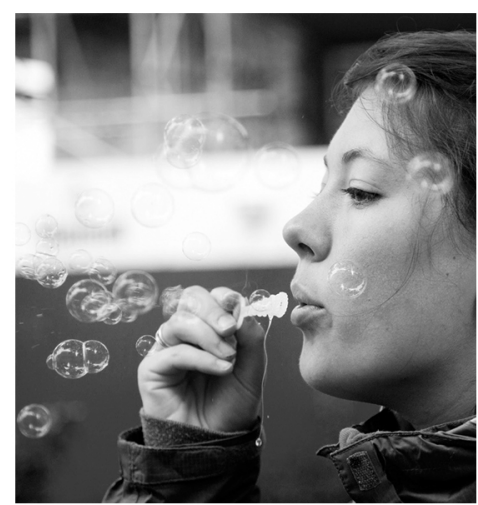

Participants were encouraged to look again at the fundamental fabric of the city and envisage it afresh. Literal and poetic drift underpinned the work - intervening into the process of city planning by holding space for i magination-fuelled conversations between a mixed set of participants on the city's streets, rather than in closed committee rooms.
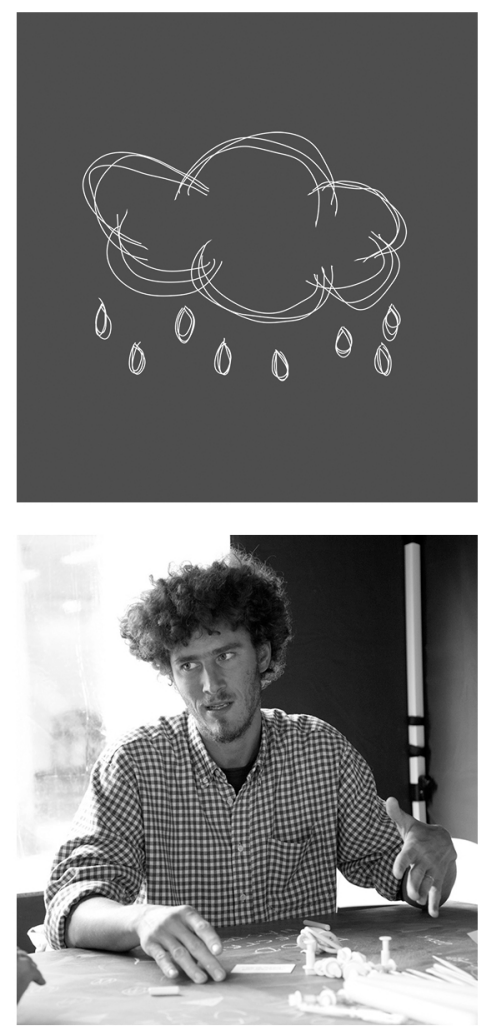

We imagined that we were visitors to the city. Inside the Tourist Information Centre, the women behind the counter served us personal secrets about the machinations of the council. We wondered about the curated displays of leaflets and touristic knick-knacks, and what they signal about the municipal framework and vision for this city.

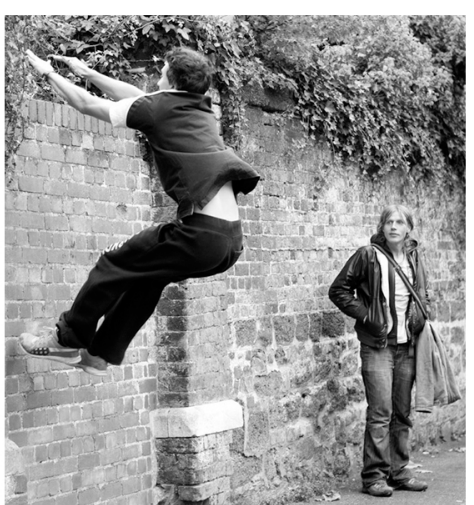

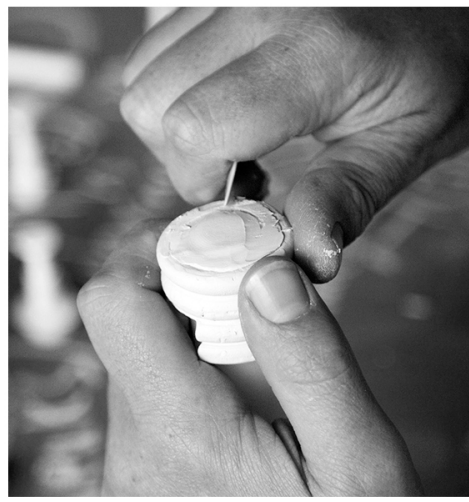

The project's first phase comprised four six-hour reconnaissance excursions, each with a different masterplanning theme: 'climate \& terrain', 'buildings \& the life between them', 'industry \& commerce' and 'mobility \& communications'. They served to 'walk and talk the work into existence', as the philosopher Herbert Lachmayer would have it.

Each walker-talker brought with them their own interests and areas of expertise, from city planning to hang gliding. And, as we walked, we encountered other tacticallypositioned experts at resonant locations, from venerable municipal officials or professional specialists (out from behind their desks or lecterns), to long-term city residents.
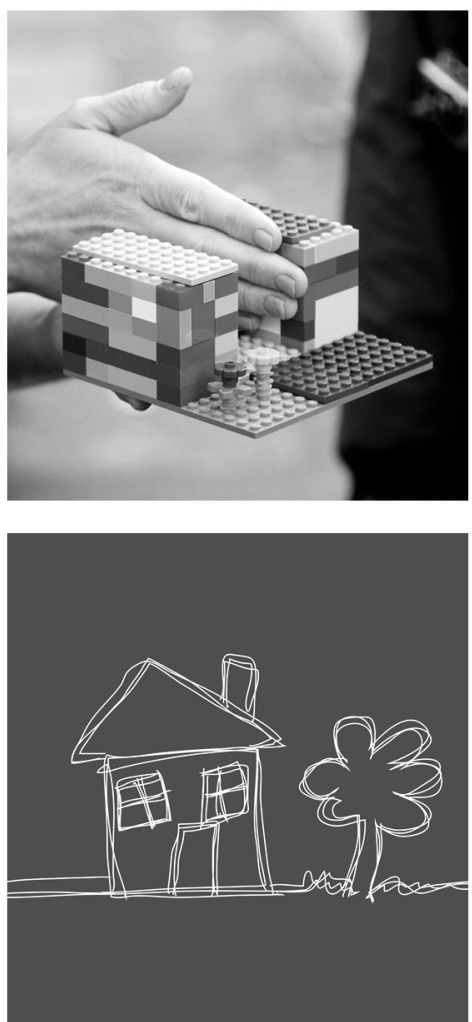
'Some roads are all about arriving or leaving' ...

... they said.

The work appeared in a different city location each day: on the quay, on the cathedral green, amid the shops, outside central station, next to the library. Out front a scale, 3-D model of the city environs. Purely topological - no buildings or human infrastructure. Accompanied by a team member, to actively engage the passing public.

It could be said, perhaps, that 'Where to build the walls that protect us' is in alignment with urban innovator Charles Landry, when he writes that: 'curiosity, imagination and creativity are the pre-conditions for inventions and innovations to develop, as well as to solve intractable urban problems and to create interesting possibilities.'
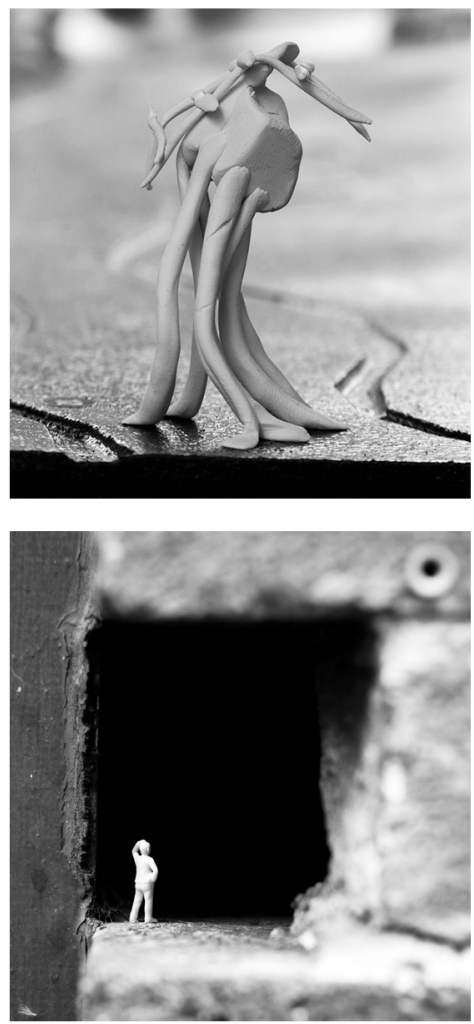

At the outset, I had proposed that I'd build and then animate a model of the city for the project's second phase, but a model can so easily be read as a finished thing - or even a disappointment, where the imagination is concerned. I decided to keep the imagination in play, to keep the project outcomes alive and evolving.
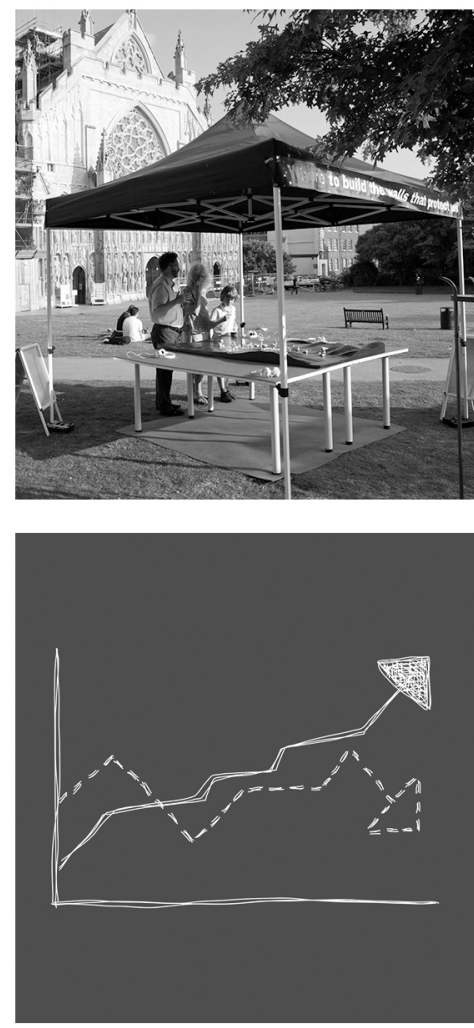

We all made and played with model worlds as children. What should we do with that creative enthusiasm now that we're all grown up? Where will we build? And where not? What's to be learned from all those unrealized plans for the city (like Thomas Sharp's 'Exeter Phoenix')? It is often said that form follows function - so what is the form where play is the function?

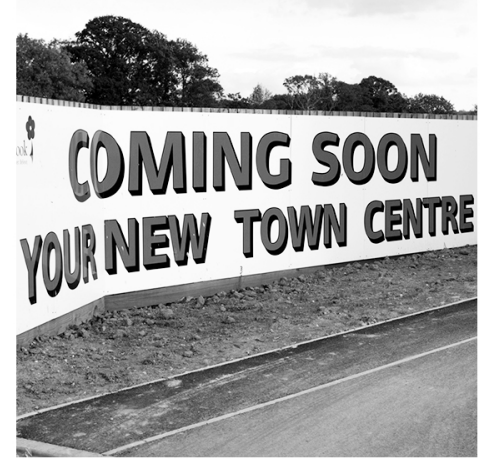

So, for the second, publicfacing phase of 'Where to build the walls that protect us', I elected not to opt for the definitive Masterplan model as originally pledged, but rather to take an iterative approach. To construct five cities in five days. Each day built from scratch. Each day catalogued, and then wiped clean. Each endpoint just one possible city.

And, for those with more time and interest, a deeper engagement could be had for the cost of one hour of time. Joining team members and future-facing, theme-related experts, they listened, talked, identified issues and questions, drew blueprint solutions, represented them in clay, and added them to the day's publicly accessible model city.

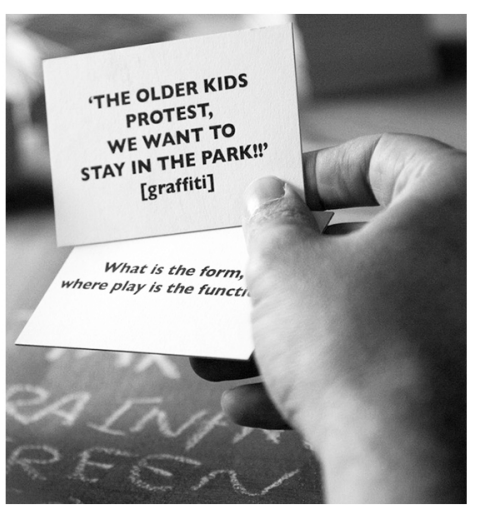

What dreams will fuel our investment plans? Can we sustain the city's momentum in its move from Clone Town to Home Town? Or balance the macro and the micro? What economic models will hold water? Should we adopt the fluidic logic of the Financephalograph? Move back to the land in Physiocratic style? Or look to SimCity for our inspiration?

We've got a river and canal, lots of roads and cycle lanes, pedestrian rights of way, and even some flightpaths. What happens if we think radically like the mayor of Bogatá, Enrique Peñalosa, and ban cars during rush hour? We have a 'house that moved' in Exeter - what about a city that walks for itself as the architect Ron Herron proposed?
The relational, indeterminate practices, which had proved so fruitful in the project's first phase, were held at the centre. Rather than creating a finished work, I found myself creating the conditions within which the work could happen - a facilitated encounter that held space within it for the project participants to imagine, to 'drift', together.
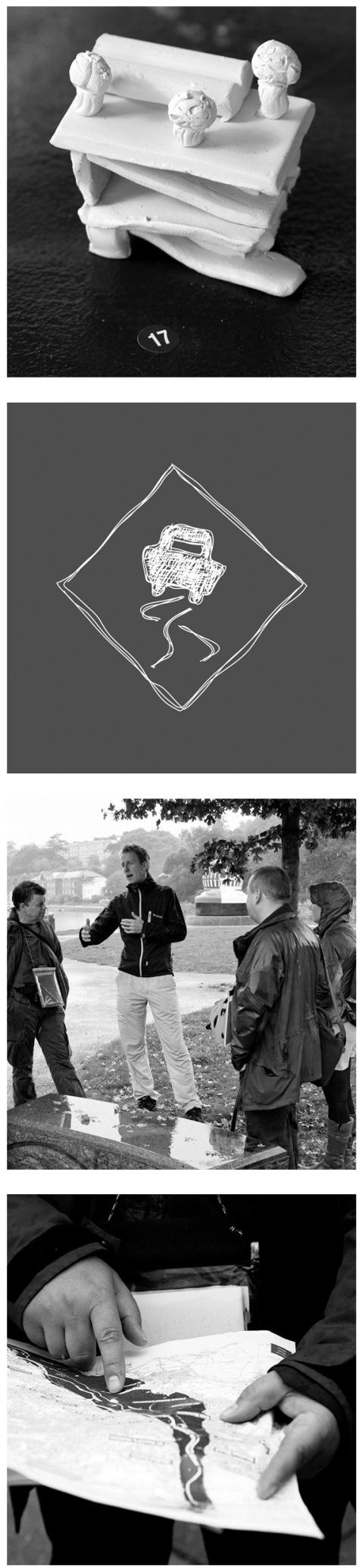